\title{
Quality of life - the factor of Russia success at present and in the future
}

\author{
S. V. Berkalov ${ }^{1}$, E. V. Pluchevskaya ${ }^{1}$, N.V. Kozlova ${ }^{1}$ \\ ${ }^{1}$ National Research Tomsk Polytechnic University, Lenin Avenue, 30, Tomsk 634050, Russia
}

\begin{abstract}
The quality of life and human development - these concepts are substantial characteristics of contemporary approaches to the challenges of economic growth and development of society. The quality of life in contemporary quality concepts means the integrated characteristics of social-economic, political, cultural-ideologic, ecologic factors and living conditions and social status of a person. State policy in the field of regulating population's quality of life and living standards is the basis of creating totally new work force, essential needs in material wealth, life quality and working conditions indicators. We consider the definition "quality of life" within the concept of human development to define the system of the factors influencing it. We review the modern approaches to the analysis of the quality of life. Features and aspects of quality of life are considered, its role in social and economic development of the country is analysed. The main criteria define specifics of human development and social wellbeing of the population. To evaluate the quality of life of the population we use the statistical analysis of the United Nations (UN), Human Development Index (HDI).We conclude that the level of life is an integrated social and economic category that presents the level of development of physical, immaterial and social needs which influence the quality of life and population wellbeing Index.
\end{abstract}

\section{Introduction}

The modern world is characterized by global changes in political as wells as in social and economic life of society, and it depends largely on reform efficiency targeting at efficiency improvement of functioning various institutions and structures. Creating the most favorable and comfortable habitat has always been, and remains the most significant challenge. Basis of laws the tendencies of continuous increase of national welfare - is in the improvement of life, meaning an intensive need of economical development in itself. Household income forms the basis of the advance in living standards and at the same time is the source of perfection and development of production for further growth of population living standards.

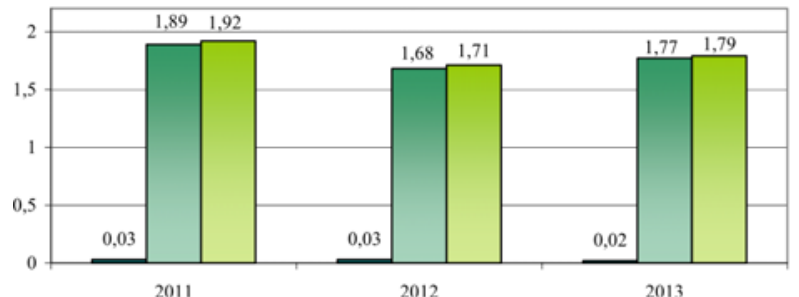

Fig. 1. Indicators of occupational diseases in the Russian Federation
1. Professional poisoning.

2. Occupational illness.

3. Occupational illness and poisoning.

In recent decades in many countries across the world including the Russian Federation the challenges of population life quality improvement have become central. Administrative reforms carried out in Russia are aimed at formation of an appropriate and effective system of state administration as soon as efficient state authorities are able to provide the conditions for increasing a population level and quality of life [8].

It is necessary to point out that the efficiency improvement of state authorities work is a complex task requiring effort concentration of society structures, authority openness to changes and population readiness to dialogue with this authority. All these require rethinking the meaning of the role and functions of the state, the nature of its interrelationship with society.

\section{Results and discussion}

At the beginning of our research it was hard to find out an unambiguous definition of the notion "quality of life". The most commonly encountered definition of "quality of life" in Russian literature is that this is a complicated synthetic category accumulating all significant living

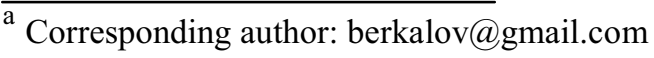


conditions, level of development and satisfaction with all system of needs and people interests [1]. The quality of life as an absolute priority of state policy has become a widespread notion in modern mass media as safety requirements, rights to dignified living and environmental conditions, freedom of self-fulfillment. We use the simplified summary of ideas of American psychologist A. Maslow as a basis determining the content of life quality evaluation criteria. His pyramid of needs presents one of the most popular and well-known motivational theories - the hierarchy theory of needs $[5$, $6]$.

The present-day interpretation of the notion "quality of life" is characterized in economics as a complicated transdisciplinary social and economic phenomenon which scientific determination was formulated as a result of fundamental analysis of the modern social regime character and nature, based on certain criterion assembly, closely connected and subordinated to each other.

Nowadays the idea about the adequate population level and quality of life is not an insignificant factor of forming an efficient state social policy.

We study the influence of citizens' social and economic wellbeing on welfare of the country totally. During the research we revealed several systems of life quality evaluation making up the notion of a man, concerning life value system from generalized up to sufficiently narrow-minded, based primarily on the level of population material wellbeing.

To evaluate the level of life quality we specify the following integrated indicators:
1. Standard of living.
2. Level of development of social infrastructure.
3. Ecological state of environment.
4. State of health.
5. Personal security.
6. Education level.
7. Quality of housing.
8. Quality of leisure and rest.
9. Family.
10. Financially economic condition of the territory.
11. Demographic situation.
12. Social confidence.

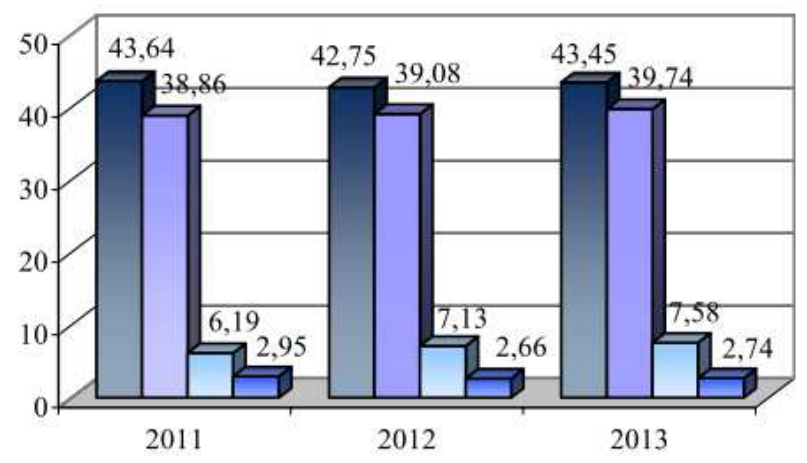

Fig. 2. Key facts and conditions of worsening of life

1. Imperfection processes.

2. Structural funds shortcomings.

3. Imperfection jobs.

\section{Inadequate sanitation facilities.}

The United Nations Economic Commission for Europe (UNECE) classifies the life quality characteristics into 8 groups: health, working place quality, buying goods and personal services, free time availability, sense of social confidence, chances for personality development, quality of environment, possibility to be in public life. It uses a life quality index to compare social and economic states of population in different countries. Since 1990 the UN have published the human development index (HDI) in the annual report.

The conception of the HDI appeared in the midfifties of the XX century due to discovery of negative consequences of the scientific and technological progress (STP) for the person. The theoretical matter of the human development concept is in the following: during the process of human potential development the possibilities of a person to chose the directions of activity are extended in three major spheres: attaining long and healthy life, knowledge acquisition, receiving access to economic resources necessary for personal self-fulfilment and an adequate standard of living. If there are no possibilities to actualize the activity in these spheres, many other people's strivings will be inaccessible as well. Hence the quality of life is defined as expansion of the opportunity to fulfill themselves at work, spiritual life and other types of activity; it includes such important components as a state of labor market, medical care quality, main social services, while saving resources for future generations, providing individual safety and equality between men and women [2,9].

The researchers started to calculate the HDI practically only in the early nineties of the XX century after the development of the appropriate methodology and creation of the uniform principles for all countries on the basis of the statistical information accumulated by the international organizations.

The HDI is calculated on the basis of three components:

- life expectancy index,

- population education index,

- real gross domestic product (GDP) per capita index.

The first index presents the generalized characteristic of population health and work efficiency of the national health care system, the second one defines the level of education system development, the third index characterizes economic opportunities of the population.

The index of human development in 2014 reflects the progress in this area made in recent years and allows seeing contemporary tendencies in the certain states. The compiled data show that the level of human development keeps growing, but the progress rates have decreased in all regions of the world and progress is very unstable. Therefore, the average annual growth rates of human development decreased almost twice in the countries of North Africa, the Middle East, the Asia-Pacific Region, and in Latin America and Caribbean as well. The sharpest decline of values of the HDI happened in the Central African Republic, Libya and Syria where the 
armed conflicts are taking place. Considering a question in all its aspects, the rate of progress of the HDI is much higher in a group of the countries with the low and average level of human development. This indicates gradual narrowing of a gap between the countries with the higher and lower level of human development.

In 2015 Norway heads the national achievements ranking, it had won the first place in the period from 2001 to 2006, then it conceded its place to Iceland, however in 2008 Norway returned to the top of the list and all this time is remaining the leader. The HDI of Norway is equal to 0,944 . The life expectancy level in this country is one of the highest in the world - 81,3 years, the average annual income per capita - \$98 860 (by the nominal rate expressed in US dollars in the current prices). Norway is the least populated state among European ones - about 4900000 people live in the country in all. There are practically no the poor there, the so-called "class differences" are very mild. Population welfare substantially depends on oil and gas and oil-refining industry, as Norway is one of the world and Western Europe largest producers and the exporters of hydrocarbons. The inflation and unemployment are traditionally low in this country in comparison with the rest part of Europe, but at the same time, Norway is one of the most expensive countries of the world.

Australia, Switzerland, the United States of America, the Netherlands, Germany, New Zealand, Canada, Singapore and Denmark are the countries with a very high level of development; they are also top ten leaders of this ranking. It is interesting that Japan which was among ten leaders in 2014 , lost seven positions at once and now it takes the 17th place [4].

The Russian Federation in the ranking of 2014 lost two positions in comparison with the previous year and took the 57 th place with the HDI equal to 0.778 , being in the top third part of the list of the countries with the high human development level. The basic indexes of Russia are the following: average life expectancy at birth is 69,1 years; the average education time is 11,7 years; a gross national income per capita is $\$ 12700$ a year. Social inequality, environmental problems, and also the low life expectancy peculiar to rather unsuccessful countries undermine the indexes of Russia. For instance, according to these indexes Russia has already been after such states as Iraq and Bangladesh. In the annual human development report 2014 it is specified that Russia (and other oil and gas export countries of the former Soviet Union) lays special emphasis on the use of natural resources, but not on economic diversification that can seriously affect sustainability and stability of human development in the following years [4]. On the other hand, we should note that Russia, nevertheless, keeps ahead the BRICS countries in the ranking. According to the report, Brazil takes the 79th place, China - the 91st (10 positions growth at once), South Africa - 118th, India - 135th among the largest states with fast-growing economy.

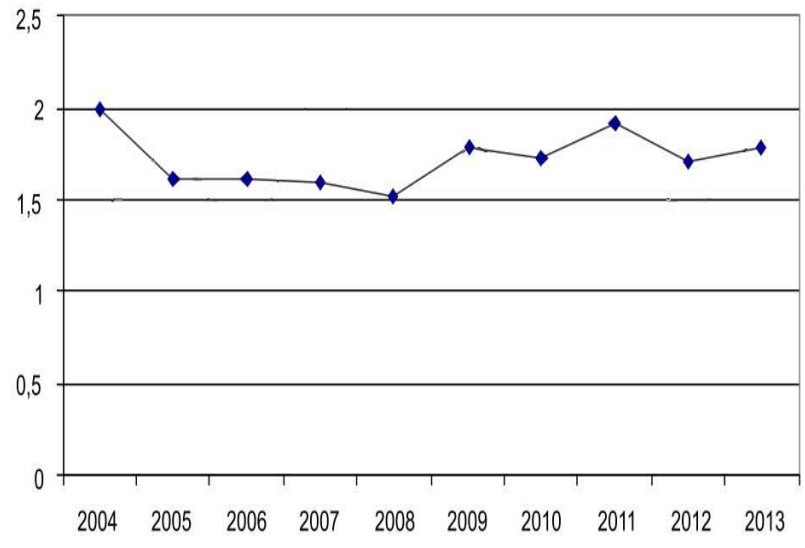

Fig. 3. Indicators of occupational diseases in the Russian Federation in 2004-2013 years

Among the FSU countries together with Russia, the following countries are included in the group with the high level of the HDI: Belarus (the 53rd place), Kazakhstan (70th), Azerbaijan (76th), Georgia (79th), Ukraine (83rd) and Armenia (87th). Other Post-Soviet states are in the group of the countries with the medium level of development: Turkmenistan (the 103rd place), Moldova (the 114th place - the lowest index in Europe), Uzbekistan (116th), Kyrgyzstan (125th) and Tajikistan (133rd). From all FSU states only the Baltic States could enter the first group of the states with the very high level of human development: Estonia takes the 33rd place, Lithuania - the 35th, Latvia - the 48th [7, 11].

The states having troubled economy with the lowest level of development close the ranking. All countries of the last five are in Africa to the South from Sahara: Sierra Leone, Chad, the Central African Republic, the Democratic Republic of Congo and Niger (the last place with HDI 0.304). The life expectancy is extremely low in these states - from 40 to 50 years, the extremely adverse social and economic environment, low literacy of the population - no more than $30 \%$ of all inhabitants can read and write, and the income per capita is less than $\$ 1000$ per person a year. Despite the partial progress made in recent years these countries still suffer from poverty, limited opportunities in education, and also the low life expectancy substantially caused by diseases and mortality, such as malaria and AIDS. In a number of the countries, these problems are aggravated with destructive consequences of armed conflicts.

Thus, the richness of the country and its development are defined not only by the GDP, but by many other indexes as well - by the indexes characterizing both the people and their social - native habitat. Modern financial and economic crisis shows exhaustibility of the existing way of world development, finality of material civilization, which puts economy and an eminence of material needs of the person in the forefront. To confront this state of affairs, there is a socio-humanistic civilization [12]. The last means the coordinated, proportional growth of components of the human capital - vital, intellectual and spiritual. In a socio-humanistic society, the economy stops being the purpose, and becomes a means of harmonious development of the 
person, thus advancing the growth of a national human wealth component.

\section{Conclusion}

A standard of living is the difficult social and economic category reflecting the income and expenses of the population, consumption and the degree of satisfaction of needs, opportunities and abilities, the education level and qualifications, organizing abilities and motivation of a person, conditions for people activity and a state of environment. Consequently, the standard of living is a complex social and economic category which reflects a level of development of physical, spiritual and social needs.

The criteria of population wellbeing, the system of various factors influence the quality of life, and, therefore, the index of population wellbeing (institutional, economic, social, ecological). Results of the research show how much the problems characterizing life quality and human health can influence the economic growth and well-being of a nation. Material prosperity, living conditions, an opportunity to have an active proper rest, a possibility to increase a cultural potential, to improve one's own health status as well as that of relatives, a state of mind all these belong to problem characteristics of life quality [10].

The level of economic development which is expressed in GDP indicators per capita is one of the important indexes, and unfortunately, it is sometimes the only indicator of life quality and level. It is not a coincidence that it is one of the generalizing indicators calculated by a technique of the $\mathrm{UN}$ for counting the HDI. According to the UN, the probable or estimated life expectancy is the most general indicator of life quality and level.

We conclude that the increase of the population living standard is a main goal of any progressive society. The state must create favorable conditions for long, safe, healthy and happy life of people, providing the economic growth and social stability in society.

\section{Acknowledgment}

This research was carried out and subsided within the framework of the Programme for enhancing Tomsk Polytechnic University's competitiveness.

\section{References}

1. V. V. Drobysheva, Vest. Tamb. Uni., 7(75), (2009)

2. E. P. Kostenko, Terra. Econom, 1, (2012)

3. A. N. Petrovichev, Prob. Sovrem. Ekonom, 2 (22), (2007)

4. Glob. Innovation Index $2015 . \quad$ From https://www.globalinnovationindex.org/content/page /gii-full-report-2015/
5. Human Development Report., 2013, From http:/www.undp.org/content/undp/en/home/libraryp age/hdr/human-development-report-2013/

6. 2014, Human Development Report., From http:/www.undp.org/content/undp/en/home/pressce nter/events/2014/july/HDR2014/

7. A. Maslow, Theory of Human Motivation (1943)

8. A.S. Alissi., Perspectives on Social Group Work Practice (New York: The Free Press, 1980)

9. A social psychological perspective /Ed, by B.Mc Laughlin (N.Y., 1969)

10. Organisation for Economic Cooperation and Development., Old age pensions (Paris, 1983).

11. I. Gough., The political Economy of the Welfare State (London: Macmillan., 1979)

12. Verband Deutscher, Rentenvesicherungstrager Renten-versicherung in Zahlen (Frankfurt, 1980) 